\title{
Cultura e regionalidade: semelhanças e diferenças nas festas do Divino Espírito Santo no território brasileiro
}

\author{
Cultura y regionalidad: similitutes y diferencias \\ en las fiestas del Divino Espíritu Santo en el territorio brasileño
}

Culture and regionality: similarities and differences
in the Holy Divine Spirit holidays in Brazilian territory

Débora B. G. Thomsen'

Rosália Maria Netto Prados"

Luci Mendes de Melo Bonini"l'

Palavras chave:

Resumo:

Regionalismo

Festa do Divino

Religiosidade e cultura

Patrimônio cultural

Estudam-se as festas do divino dos municípios de Mogi das Cruzes SP, Alcântara - MA, Pirenópolis - GO, São João Del Rei - MG e Vale do Guaporé-MT- RO a fim de se identificar eventos folclóricos, religiosos e profanos, bem como apontar políticas locais de preservação de patrimônio histórico, cultural - material e imaterial. Optou-se pelo método de revisão bibliográfica e documental - tanto documentos oficiais como documentários expostos nas redes sociais e páginas oficiais dos municípios. Os resultados demonstraram que as festas do Divino em várias regiões do Brasil são bastante semelhantes dadas as origens portuguesas. Não se encontrou, na maioria dos casos, políticas culturais de reconhecimento de patrimônio cultural, mas sim, de incentivos turísticos em algumas delas. 


\section{Resumen:}

Se estudian las fiestas del divino de los municipios de Mogi das Cruzes - São Paulo, Alcantara - Maranhão, Pirenópolis - Goiás, São João Del Rei - Minas Gerais y Valle del Guaporé - Mato Grosso y Rondônia a fin de identificar eventos folclóricos, religiosos y Profanos, así como apuntar si existen políticas locales de preservación de patrimonio histórico, cultural - material e inmaterial. Se optó por el método de revisión bibliográfica y documental - tanto documentos oficiales como documentales expuestos en las redes sociales y páginas oficiales de los municipios. Los resultados demostraron que las fiestas de lo divino en varias regiones de Brasil son bastante similares a las orígenes portuguesas. No se ha encontrado, en la mayoría de los casos, políticas culturales de reconocimiento de patrimonio cultural, sino, Incentivos turísticos en algunas de ellas.
Palabras clave:

Regionalismo

Fiesta de lo Divino

Religiosidad y cultura

Patrimonio cultural

\section{Keywords:}

Regionalism

Holy Ghost Feast

Religion and culture

Cultural heritage

\section{Abstract:}

This paper presents a research about the Holy Ghost feast in different municipalities in Brasil: Mogi das Cruzes - São Paulo, Alcântara Maranhão, Pirenópolis - Goiás, São João Del Rei - Minas Gerais and Vale do Guaporé - Mato Grosso and Rondônia in order to identify folk, religious and secular events, as well as local political point of preservation historical, cultural heritage - tangible and intangible. The method was the bibliographical and documental review- both official documents as documentaries exposed in social networks and official pages were chosen to clarify the objects studied here. The results showed that the parties of the divine in various regions of Brazil are quite similar because the Portuguese sources. It was not found, in most cases, cultural policies cultural heritage recognition, but tourist incentives in some of them. 


\section{Cultura e regionalidade: semelhanças e diferenças nas festas do Divino Espírito Santo no território brasileiro}

\section{Introdução}

As festas religiosas são consideradas manifestações importantes e necessárias para integração da comunidade, representação da cultura e memória local, além de propiciar a valorização da expressão coletiva. Nessas comemorações os devotos podem manifestar com liberdade suas crenças e sua fé, aguçados por um ideal de igualdade e solidariedade (ARAÚJO, 2004).

De acordo com Lossio e Pereira (2007), as manifestações populares que apresentam um contexto regional, representam uma identidade cultural e são um incentivo ao desenvolvimento local. Para os autores, devemos considerar que essa representação cultural popular, com o passar do tempo, sofre alterações em função de mudanças no panorama econômico, administrativo, educativo, social e político da região bem como as políticas públicas envolvidas na valorização da manifestação social.

No contexto globalizado em que vivemos, a facilidade na comunicação altera a dinâmica dessas manifestações folclórico-religiosas já que a divulgação pode acontecer em larga escala, atraindo turistas e empreendedores. De acordo com Simões (2006), esse tipo de turismo apresenta interesses econômicos, mas também colabora com o desenvolvimento local.

Em conformidade com o exposto, a UNESCO (1989) reconhece que a cultura tradicional e popular, fundamentada em tradições, é expressa por um grupo ou indivíduos e representa a identidade de uma comunidade.
Em 1989 a UNESCO organizou uma recomendação para a salvaguarda da cultura tradicional e popular. Nela, a organização enfatiza o valor desses patrimônios imateriais como a aproximação entre os diferentes povos e grupos sociais, a afirmação da identidade cultural, sua importância para o desenvolvimento social, econômico, cultural, político e histórico de uma nação. A Conferência Geral também reconheceu a fragilidade dessas formas de cultura, principalmente quando essas tradições são orais.

Assim, recomenda aos Estados medidas legislativas ou outras que sejam necessárias, para fomentar e preservar essas representações culturais. Neste sentido, este texto busca traçar alguns pontos que possam justificar o debate. Alguns levantamentos podem iluminar alguns cantos da necessidade de se buscar políticas mais eficazes no reconhecimento do patrimônio cultural brasileiro a fim de promover a cultura, o turismo e enfrentar o desmonte do sentimento de pertencimento que a globalização ameaça.

Regionalmente as festas religiosas se diferenciam umas das outras por apresentarem influências de fatores socioeconômicos, étnicos, tradições e memória coletiva. Em alguns lugares as festividades contam apenas com missas e quermesses, em outras localidades as tradições, o colorido da festa, os aspectos folclóricos e históricos, transformam as comemorações em um evento de grande porte (ARAÚJO, 2004).

Neste sentido, trabalho tem como objetivo estudar a Festa do Divino em algumas regiões do país de modo a identificar atividades relacionadas à ao folclore, à religiosidade, atividades culturais e turísticas e se existem políticas locais que as salvaguardam.

Os resultados demonstraram que as festas do divino em várias regiões do Brasil são bastante semelhantes dadas as origens portuguesas, a tradição oral vem sustentan- 
do essas atividades e não se encontrou, na maioria dos casos, políticas culturais de reconhecimento de patrimônio cultural, mas sim, de incentivos turísticos em algumas delas.

\section{Método}

Esta pesquisa é de natureza descritiva de abordagem qualitativa. A fim de poder descrever cada localidade, suas características e as de cada Festa do Divino, utilizou-se a revisão da literatura: artigos, livros teses e dissertações encontradas em portais acadêmicos de modo que se pudesse ter uma visão ampla sobre cada uma delas. Foram realizadas revisões tendo como base de informação os portais oficiais das prefeituras, blogs oficiais e canais do YouTube de devotos ou simplesmente pessoas interessadas para detalhamento de eventos ou ainda de dados sobre as políticas locais.

\section{Cultura e regionalidade: a Festa do Divino no Brasil}

De acordo com Simões (2006), as identidades e as culturas são móveis, elas se deslocam e redefinem fronteiras. Seus componentes podem originar-se em uma região e migrar para outras, e assim, podem evidenciar suas características ou miscigenar-se com outra cultura:

Nesse âmbito, os trânsitos contribuem para reflexões sobre tensões, convergências e divergências entre o local, o nacional e o global, tendo em conta que a globalização promove movimentos migratórios em relação ao local e acentua as suas questões identitárias. (SIMÕES, 2006, p. 10).

A Festa do Divino Espírito Santo, inicialmente era relacionada aos antigos rituais pagãos do culto aos vegetais, contudo, logo depois foi protegida pela Igreja e passou a ser utilizada como forma de evangelização. Atualmente ela é considerada a manifestação católica mais antiga de que se tem conhecimento em Portugal e no Brasil. Datando de 1321, essa festividade representa uma comemoração às graças concedidas pela terceira pessoa da Santíssima Trindade, o Espírito Santo e originou-se em Portugal, mas posteriormente foi difundida pelo mundo. (BONINI; PEREIRA, 2015)

É provável que a celebração tenha chegado ao Brasil no século XVI e a partir daí, espalhou-se e foi sendo modificada para adaptar-se às diferenças regionais do país. Encontram-se particularidades socioeconômicas, étnicas, tradicionais e relacionadas à memória coletiva, o que faz com que cada festa tenha sua particularidade, sua identidade (ARAÚJO, 2004).É importante destacar que o devoto, participante ativo das festividades em homenagem ao Divino, é o exemplo de expressão da crença popular (CHAVES, 2010).

A festividade conta ainda com a participação do seu personagem mais característicos, o imperador, ou casal de imperadores, que em algumas cidades são representados por crianças, em outras são utilizados adultos nesta função. Eles significam "alguém do povo que é escoIhido para ser o mensageiro da palavra de Deus". Em algumas cidades seus encargos são apenas simbólicos, aparecendo para realizar alguns protocolos nas celebrações, já em outras localidades, eles realizam parte da organização da festa, arrecadação de fundos, e orações.

Em algumas festas, as atrações apresentadas, tais como cantores, shows, etc., nem sempre são regionais, mas são consideradas importantes e possuem grande visibilidade por impulsionarem o turismo e, consequentemente, a economia do local, e por isso, são valorizadas em detrimento do fortalecimento da comunidade e de seus artistas populares. 
Pensando nos benefícios relacionados à identidade local, ao desenvolvimento econômico e nas possibilidades de estímulos à cultura, turismo e comércio (setores formais e informais) de uma determinada região, o governo por meio do Ministério da Cultura, criou alguns projetos direcionados à valorização das manifestações culturais como a Lei Federal de Incentivo à Cultura (Lei $\left.n^{\circ} 8.313 / 91\right)$, a Lei Rouanet, e a Lei do Audiovisual (Lei $n^{\circ}$ 8.685/93) (BRASIL, 2017). Esse apoio é fundamental para que a relação entre cultura e desenvolvimento seja complementar, e, assim, consolide a diversidade como um direito, visto que, "o núcleo da relação entre cultura e desenvolvimento em países como o Brasil passa, necessariamente, pelo tenso equilíbrio entre diversidade cultural e desigualdade social" (ALVES, 2010).

\section{Festa do Divino: Mogi das Cruzes - São Paulo}

A cidade de Mogi das Cruzes está localizada na região sudeste do estado de São Paulo, distante $50 \mathrm{~km}$ da capital, São Paulo. Possui uma população estimada de 429.321 habitantes (IBGE, 2016) sendo que em 2010 eram 387.779 (IBGE, 2010). Destes, 199.604 são católicos $(51,47 \%$ da população contabilizada em 2010), e 114.148 são evangélicos (29,44\%) (IBGE, 2010). A cidade foi fundada em 1611 por Gaspar Vaz, e surgiu em função dos bandeirantes.

A tradicional Festa do Divino Espírito Santo de Mogi das Cruzes acontece 50 dias após a Páscoa e celebra o dia de Pentecostes. São 404 anos de devoção. Esse é um dos motivos que a faz ser considerada patrimônio cultural da cidade (SILVA; SANTOS; BONINI, 2017).A prefeitura reconhece a tradição, o valor histórico, o envolvimento religioso e os aspectos culturais relacionados, tanto que fundou o Museu da Festa do Divino Espírito Santo que objetiva preservar a memória e valorizar os bens advindos das comemorações além de sediar uma das celebrações de abertura da festa.

Identificada como Patrimônio Imaterial da cidade desde 2009, a Festa do Divino valoriza a expressão folclórica-religiosa dos antigos moradores que praticavam a adoração ao Espírito Santo, desde o século XVII. Considerada uma das festas mais antigas do Brasil, a festa de Mogi das Cruzes é responsável pela mobilização de 3000 voluntários, aproximadamente, devotos e visitantes, que juntos somam mais de 400 mil pessoas participantes nos mais de 60 eventos relacionados à festividade (BONINI; PEREIRA, 2015).

Em Mogi das Cruzes há um cortejo intitulado Entrada dos Palmitos: uma procissão com carros de boi e cavaleiros - muito enfeitados com palmitos: vegetal abundante na região em décadas passadas. Esse cortejo traz os devotos com seus cavalos e cavaleiros enfeitados, com suas bandeiras para honrar e demonstrar sua devoção à terceira pessoa da santíssima Trindade. Saem à frente os festeiros e capitães do mastro, ex-festeiros, personalidades políticas e convidados, em seguida grupos de devotos que se dividem por sentimento de pertencimento: jovens, idosos, crianças, rezadeiras, muitos vestidos de vermelho e, na sua maioria, com as bandeiras. Mais atrás das pessoas vêm os grupos de congadas e marujadas honrando seus padroeiros, com seus tambores e ritmos, por último os carros de boi enfeitados com legumes, flores e frutas, e os cavaleiros que vêm de cidades e distritos mais distantes do centro da cidade, para onde se dirige a procissão que passa pelo altar do divino erigido em frente à Catedral de Santana e segue depois para o local da quermesse onde os romeiros vão se alimentar com o afogado do povo: uma distribuição gratuita de uma sopa feita de batata com carne de vaca (BONINI; PEREIRA, 2015).

Assim como todas as festas religiosas a quermesse acontece todas as noites num local específico que a prefeitura 
da cidade organiza todos os anos a fim de dar conta da grande massa que a cidade recebe, dada as dimensões da festa.

Um dos ritos religiosos que acontecem ao longo da festa é a Alvorada: durante 9 dias, a partir das 5 horas da manhã, os devotos se reúnem em frente da Catedral de Santana, saem por uma procissão que se arrasta pelo centro da cidade e rezam a Coroa do Divino, esta ação representa uma antiga manifestação realizada pelos devotos que buscavam doações para a realização da Festa do Divino, passando de casa em casa, rezando e abençoando as famílias que doavam prendas para a festa. São diferentes trajetos: hospital, cemitério e igrejas. A procissão assim se organiza: na frente os lanterneiros, em seguida rezadores e rezadeiras acompanhados do carro de som e atrás desses os devotos, mais de duas mil pessoas participam das alvoradas ao longo da festa (BONINI; PEREIRA, 2016).

No último dia da Festa ocorre uma procissão ao Divino Espírito Santo, que parte da Catedral de Santana e caminha pelas ruas do centro da cidade. O cortejo faz sete paradas durante o percurso em reconhecimento aos setes dons do Espírito Santo - Fortaleza, Ciência, Conselho, Sabedoria, Piedade, Entendimento e Temor do Senhor. Para essa procissão, devotos voluntários de toda a cidade confeccionam tapetes decorados feitos com serragem, pó de café, casca de ovo, areia colorida, entre outros materiais.

Desde o início do ano, as rezadeiras realizam um trabalho de peregrinação visitando mais de 2 mil casas, e atendendo cerca de 33 mil devotos. Durante essas visitas, elas recolhem pedidos ao Divino Espírito Santo (BONINI; PEREIRA, 2016).

O encerramento da festa se dá após a celebração de Pentecostes, com a incineração dos pedidos realizados pelos devotos e entregues às rezadeiras ou depositados nas urnas instaladas no Império (altar do
Espírito Santo). A queima dos pedidos simboliza a elevação dos mesmos ao céu.

Para identificação dos devotos e agentes das festividades, tradicionalmente são utilizadas bandeiras vermelhas, com uma pomba (representação popular do Espírito Santo, conforme referências bíblicas) no centro. Todas possuem características comuns como fitas coloridas trançadas, a pomba envolta por ornamentação, e os dons do Espírito Santo representados. Sempre utilizando as cores vermelho e branco, esse ícone, na maioria das vezes, é feito à mão (VALIM; PRADOS; BONINI, 2015).

\section{Festa do Divino: Alcântara - Maranhão}

A cidade de Alcântara está localizada na região norte do estado do Maranhão, distante $30 \mathrm{~km}$ da capital, São Luís. Possui uma população estimada de 21.667 habitantes (IBGE, 2016) sendo que em 2010 eram 21.851 (IBGE, 2010). Destes, 12.658 são católicos (58\% da população contabilizada em 2010), e 4.249 evangélicos (19,44\%) (IBGE, 2010). A cidade foi fundada em 1648 quando a aldeia elevou-se a categoria de vila. Esse território, antes habitado por índios, passou a ser colonizados por franceses e logo em seguida, por portugueses.

Entre as celebrações realizadas durante os dias de festa, ocorrem missas na igreja matriz, apresentação dos membros da corte no Palácio Imperial de Alcântara (crianças entre 4 e 14 anos utilizando trajes de época da corte de imperadores e mordomos), cortejo ao Divino e levantamento do mastro. Durante todas as etapas da cerimônia, as caixeiras, senhoras que tocam caixa e entoam cânticos em louvor ao Divino Espírito Santo, embalam a festa. Esses cânticos são acompanhados pelas caixeiras, mulheres consideradas sacerdotisas que conduzem os rituais festivos da Festa do Divino (GOMES; GASTAL; CORIOLANO, 2015). As caixas são instrumentos de percussão que acompanham 
os cânticos, resgatando a herança cultural africana, muito presente na região, já que Alcântara possui comunidades remanescentes de quilombos que mantém as características dos seus ancestrais. Os cânticos entoados podem ser improvisados ou decorados, individuais ou coletivos (GOMES, 2017).

É importante salientar que Alcântara foi a primeira cidade histórica amazônica a ser reconhecida como Patrimônio Nacional, desde 1948, por sua riqueza cultural e arquitetônica. A cidade mantém viva grandes tradições culturais e a convivência em comunidade e merece destaque pela presença de inúmeras ruínas coloniais, consideradas atrativos turísticos, tais como a Capela das Mercês, 1656; Praça da Matriz, 1648; Igreja de São Matias, 1869; Pelourinho; Igreja e Convento de Nossa Senhora do Carmo, 1665; Forte de São Sebastião, 1797; Igreja de Nossa Senhora do Rosário dos Pretos, 1781; entre outras (GOMES, 2017). Em 1983, em Alcântara, foi criado o Centro de Lançamentos de Alcântara para implementação de atividades espaciais. Essa criação gerou grandes impactos sociais, econômicos e ambientais pois retirou diversas comunidades quilombolas de suas áreas originais, em função da desapropriação para fins de interesse nacional, ocupando praticamente toda a área litorânea da cidade (GOMES, 2017).

As festas no Maranhão apresentam algumas particularidades como as caixeiras e a união da festa católica a religiões praticadas em terreiros de tambor de mina - casas de culto afro-maranhense, principalmente em São Luís (FERRETI, 2005). No entanto, em Alcântara, a festa é de base católica, e as caixeiras entoam cânticos em devoção ao Espírito Santo, exclusivamente.

Fazem parte das festividades realizadas no Maranhão, um casal de imperadores, de mordomo régio, mordomo mor, os padrinhos do mastro e outros colaboradores. Em seguida, escolhem-se as co- res das vestimentas que serão utilizadas pelas crianças e por toda a decoração da festa. É costume haver ao amanhecer, ao meio dia, e ao anoitecer, uma salva de caixas, denominada alvorada.

O levantamento do mastro indica o início da festa e é realizado à noite e sua derrubada assinala a finalização da festa.

Ao participarem das festividades, os turistas entram em contato com o cotidiano, a gastronomia, e o estilo de vida local. O comércio ambulante de comidas e bebidas se intensifica, no entanto, surgem atividades de cunho puramente comercial, como os clubes de reggae:

Este evento religioso estimula a participação ativa dos visitantes: no levantamento do mastro, nas missas e ladainhas, na visita aos mordomos, ou seja, os espaços de convivência comunitária transformam-se em espaços materiais e simbólicos onde bens, serviços, patrimônios e elementos da cultura circulam entre anfitriões e hóspedes. (CARVALHO, 2016, p. 13).

Segundo Gomes (2017), as comemorações na cidade estão passando por sérias dificuldades de perpetuação em função da falta de renovação das caixeiras, geradas pelo desconhecimento, desinteresse e falta de incentivos; a viagem em embarcações, em condições precárias, que dá acesso à cidade; a falta de estrutura de restaurantes e hotéis. No entanto, a gestão municipal e estadual vem se comprometendo a estimular e financiar a manutenção das tradições da cidade e a sensibilização da população local.

\section{Festa do Divino:}

\section{São João Del Rei - Minas Gerais}

A cidade de São João del Rei está localizada na região sudeste de Minas Ge- 
rais, distante $187 \mathrm{~km}$ da capital, Belo Horizonte. Possui uma população estimada de 89.832 habitantes (IBGE, 2016) sendo que em 2010 eram 84.469 (IBGE, 2010). Destes, 72.048 são católicos $(85,3 \%$ da população contabilizada em 2010), e 7.271 evangélicos (8,6\%) (IBGE, 2010). A cidade foi fundada em 1713 pelo Governador D. Braz Balthazar da Silveira, e desenvolveu-se em virtude da intensa mineração na região.

A festa em adoração ao Divino Espírito Santo, na cidade de São João del Rei, iniciou-se, provavelmente, com a inauguração da igreja do Senhor Bom Jesus de Matosinhos, em 1774. Possui um imperador perpétuo, Santo Antônio, eleito pela população, coadjuvando com o Divino Espírito Santo. Conta como principais eventos associados às festividades, as folias (visitas às casas recolhendo donativos para as comemorações); a cavalgada do divino (ocorre nas ruas da cidade); os mastros do Divino e Santo Antônio; procissão do imperador perpétuo, entre outros (PORTAL DO DIVINO, 2017).

Em São João del Rei, comemora-se o Jubileu Perpétuo, uma festa religiosa que possibilita indulgência aos fiéis arrependidos, que confessarem, comungarem, e visitarem a capela de Nosso Senhor Jesus Cristo de Matosinho e fizerem orações a Deus em favor da santa propagação da fé (PASSARELLI, 2004).

A festa sofreu uma paralisação em 1923 quando a Conferência Episcopal da Província de Mariana proibiu a festa, que só voltou a ganhar força e representatividade em 1997. Nessa data ela começou a apresentar características que se repetem todos os anos: a fase preparatória das festividades ocorre quando as ruas do município são percorridas pelas Folias do Divino, que são grupos folclóricos responsáveis por angariar donativos para a festa. No domingo que antecede a festa acontece a Cavalgada do Divino, onde cavalei- ros circulam pelas ruas das cidades, junto com as bandeiras do Espírito Santo.

As festividades se iniciam com o levantamento do mastro, na sexta feira. No sábado, véspera de Pentecostes é realizada a Missa Inculturada - com rituais que seguem as tradições africanas. No sábado é realizada a Procissão do Imperador Perpétuo seguida de bandeiras, músicas e folias. No domingo de Pentecostes transcorre a alvorada, missa, apresentação de grupos de congadas, marujadas, catuapés, bate-paus e moçambiques, seguidos de danças-de-fitas e pastorinhas. Depois, vem o Cortejo Imperial e a coroação do novo Imperador. Para finalizar as celebrações ocorre a descida do mastro (PASSARELLI, 2004; PORTAL DO DIVINO, 2017).

\section{Festa do Divino: Pirenópolis - Goiás}

O município de Pirenópolis está localizado no centro do estado de Goiás, distante $130 \mathrm{~km}$ da capital, Goiânia. Possui uma população estimada em 24.604 habitantes (IBGE, 2016), sendo que em 2010 eram 23.006 (IBGE, 2010), destes, 16.294 são católicos. A cidade foi fundada em torno das primeiras décadas do século XVIII, por Manoel Rodrigues Tomar e surgiu em função das atividades mineradoras na região. (IBGE, 2017)

\section{Em 1990 o município foi tombado} como conjunto arquitetônico, urbanístico, paisagístico e histórico, pelo IPHAN. Possui casarões e igrejas do século XVIII como a Matriz de Nossa Senhora do Rosário de 1732 (PIRENOPOLIS, 2017). Na cidade, as comemorações em homenagem ao Espírito Santo, envolvem as Cavalhadas - encenações dramáticas da batalha entre mouros e cristãos pelo domínio da península Ibérica e são animadas por diversos mascarados.

Acredita-se que as festas foram se difundindo em Goiás à medida que a Igreja 
expandia e ocupava novos espaços assumindo uma cultura colonizadora por meio dos jesuítas. Em Pirenópolis, a festa ganhou grande enfoque quando a cidade perdeu sua importância econômica em Goiás, e assim, buscou dinamizar seus festejos em função da valoração da expressão da sociedade. No entanto, é importante observar que a Romanização da Igreja Católica exigiu das entidades religiosas, posturas diferentes das que vinham sendo tomadas, inclusive redefinindo manifestações católicas populares (SILVA, 2000).

Em contrapartida, a população local criou um vínculo inestimado com a festividade, entendendo as comemorações como identidade cultural da comunidade e, por esse motivo, busca formas de viabilizar a manutenção das tradições respeitando os mecanismos de produção e reprodução da festa que são responsáveis por promover o intercâmbio abundante de bens materiais e simbólicos durante as festividades (SOARES, s/d)

As festividades do divino se iniciam com as folias do Divino, onde cavaleiros percorrem a zona rural da cidade, com o objetivo de levar bênçãos e captar recursos para a festa; muitas cantorias são entoadas em homenagem ao Paráclito. As cavalhadas acontecem logo após as folias do Divino. São três dias de comemorações que simbolizam as lutas na idade Média. A cidade construiu um "cavalhódromo" para a realização das dramatizações. Nos dois primeiros dias ocorre a encenação das lutas, com a vitória cristã e a conversão dos mouros que é quando acontece a evocação do Divino Espírito Santo. No terceiro dia, ocorrem provas de habilidades envolvendo todos os cavaleiros (PIRENÓPOLIS, 2017; SILVA, 2000).

Alguns homens, chamados de "curucucus", a pé ou a cavalo, utilizam fantasias muito criativas e máscaras, brincam e fazem barulho pelas ruas da cida- de. As máscaras mais populares são de boi, onça e diabo. (PIRENÓPOLIS, 2017)

Um dado importante sobre a Festa do Divino em Pirenópolis é que, assim como ocorreu em outras localidades, antigamente a festa era totalmente patrocinada e organizada por uma única família, de alto poder aquisitivo, da cidade. O mantenedor da família era considerado o Imperador do Divino e a festa se moldava aos padrões estabelecidos por essa família (SILVA, 2000).

\section{Festa do Divino: Vale do Guaporé - Mato Grosso - Rondônia}

$O$ rio Guaporé nasce na cidade de Pontes e Lacerda (MT), penetra no estado de Rondônia e compõe a divisa natural entre Brasil e Bolívia, desaguando no Rio Mamoré, no município de Costa Marques (RO). O vale apresenta inúmeras áreas de preservação além de seu valor histórico com a presença de lendas indígenas e ribeirinhas e manifestações populares (RONDÔNIA, 2017).

No Vale do Guaporé, o cortejo do Divino acontece de uma forma particular: uma procissão fluvial que percorre mais de 35 localidades brasileiras e bolivianas. Assim como algumas outras festas, como Piracicaba e Anhembi, no interior de São Paulo, essa festa é realizada utilizando-se o rio. A procissão, uma tradição herdada dos negros, já acontece há 123 anos e atrai devotos de muitos lugares do Brasil e dos países vizinhos. Ela se inicia no domingo de Páscoa em uma cidade escolhida e culmina em uma festividade que dura sete dias encerrando todas as comemorações no Dia de Pentecostes (CRUZ, 2016).

Dentro do Barco do Divino se encontra uma Arca contendo a Coroa, a bandeira, as toalhas do altar e os livros de ata da festividade (BORGES, 2017). O barco é movido por um pequeno motor que é desligado quando a embar- 
cação se aproxima de uma localidade e inicia-se remadas cadenciadas que levam o barco até o porto. Quando o barco aporta, o responsável pela Coroa desembarca e é recebido pelo Imperador local, ao som de muita cantoria e orações (PAKAAS, 2017).

\section{Semelhanças culturais entre as Festas do Divino}

Segundo Mariano (2009), essas demonstrações religiosas atuam de forma dinâmica, acompanhando a evolução e as mudanças econômicas e culturais da localidade, misturando o rural com o urbano; o catolicismo rústico com o culto à natureza; o tradicional com o moderno, pois: "em função da manutenção da tradição os recursos modernos que tendem a destruí-la são utilizados, causando a sua reprodução, embora de forma espetacular, ou seja, no processo de transformação da Festa em mercadoria." (MARIANO, 2009, p. 14)

E assim tradicionalmente, continua a autora: "a Festa implica ligação com o passado que se atualiza no presente, voltada para o futuro (...)" (Idem, ibidem, p. 3).

Ao se organizar o quadro a seguir, intentou-se alinhar as questões culturais assim como debruçou-se nas páginas dos governos locais a fim de se vislumbrar referências que demonstrassem interesse na preservação dos patrimônios culturais, dentro do que ensina a UNESCO:

A preservação respeita a proteção das tradições que revelam da cultura tradicional e popular e dos seus detentores, na consideração que cada povo detém direitos sobre a sua própria cultura e de sua adesão a essa cultura pode enfraquecer-se por influência da cultura industrializada difundida através dos meios de comunicação (UNESCO, 1989, p. 4).

\section{(...)}

A cultura tradicional e popular, na medida que é constitutiva de manifestações de criatividade intelectual, individual ou coletiva, merece proteção análoga à que se confere às produções intelectuais. Tal proteção da cultura tradicional e popular revela-se como meio indispensável para o melhor desenvolvimento, perpetuação e difusão deste patrimônio, quer no país como no estrangeiro, sem prejuízo dos legítimos interesses nele implicados (UNESCO, 1989, p. 6)

E que o Brasil bem buscando acompanhar, pois um marco legal voltado ao "Registro de Bens Culturais de Natureza Imaterial que constituem o patrimônio cultural brasileiro" é o Decreto 3.551/2000. O responsável por atuar nessa área é o Instituto de Patrimônio Histórico e Artístico Nacional (IPHAN), por meio do Departamento de Patrimônio Imaterial (DPI).

(...) compreende o Patrimônio Cultural Imaterial brasileiro como os saberes, os ofícios, as festas, os rituais, as expressões artísticas e lúdicas, que, integrados à vida dos diferentes grupos sociais, configuram-se como referências identitárias na visão dos próprios grupos que as praticam. Essa definição bem indica o entrelaçamento das expressões culturais com as dimensões sociais, econômicas, políticas, entre outras, que articulam estas múltiplas expressões como processos culturais vivos e capazes de referenciar a construção de identidades sociais (CASTRO; FONSECA, 2008, p. 12)

No sentido de se identificar certos caminhos que estão sendo trilhados na patrimonialização das festas do Divino de algumas regiões do país, buscou-se elaborar um quadro com informações presentes nas fontes consultadas a fim de se tecer comparações entre elementos culturais: sagrados e profanos, bem como de políticas locais para apoio da manutenção das tradições: 


\section{Quadro 1. Descrição de elementos culturais e políticas locais de algumas festas regionais do Divino no Brasil}

\begin{tabular}{|c|c|c|c|c|}
\hline Município & $\begin{array}{l}\text { Manifestações } \\
\text { Religiosas }\end{array}$ & Símbolos & $\begin{array}{l}\text { Manifestações } \\
\text { folclóricas }\end{array}$ & $\begin{array}{c}\text { Políticas } \\
\text { locais para } \\
\text { patrimonialização }\end{array}$ \\
\hline $\begin{array}{l}\text { Mogi das } \\
\text { Cruzes - SP }\end{array}$ & $\begin{array}{l}\text { - Alvoradas } \\
\text { - Missas } \\
\text { - Novenas } \\
\text { - Coroa do divino } \\
\text { - entoadas pelas } \\
\text { rezadeiras }\end{array}$ & $\begin{array}{l}\text { - Coroa } \\
\text { - Cetro } \\
\text { - Pomba } \\
\text { - Bandeira vermelha } \\
\text { com fitas } \\
\text { - Fogo para queima } \\
\text { dos pedidos }\end{array}$ & $\begin{array}{l}\text { - Congadas } \\
\text { - Marujadas } \\
\text { - Entrada dos Palmitos } \\
\text { - Folias do Divino para } \\
\text { captar recursos } \\
\text { - Imperadores crianças }\end{array}$ & $\begin{array}{l}\text { - Decreto municipal n }{ }^{\circ} 7970 / 2007 \\
\text { que patrimonializou a festa do } \\
\text { Divino, as congadas, o afogado } \\
\text { - comida típica servida na festa } \\
\text { para os romeiros } \\
\text { - Criação do Museu do Divino } \\
\text { em } 2010 \text {. }\end{array}$ \\
\hline $\begin{array}{l}\text { Alcântara } \\
\text { - MA }\end{array}$ & $\begin{array}{l}\text { - Missa } \\
\text { - Alvoradas - com as } \\
\text { caixas: manhã, } \\
\text { tarde e noite }\end{array}$ & $\begin{array}{l}\text { - Pomba } \\
\text { - Mastro } \\
\text { - Bandeiras } \\
\text { vermelhas }\end{array}$ & $\begin{array}{l}\text { - Caixeiras } \\
\text { - Imperadores } \\
\text { crianças } \\
\text { - Cortejo de } \\
\text { levantamento } \\
\text { de mastro }\end{array}$ & $\begin{array}{l}\text { - A cidade é Patrimônio } \\
\text { nacional desde } 1948 \\
\text { - Patrocínio financeiro } \\
\text { vem do governo do } \\
\text { Estado e da prefeitura. }\end{array}$ \\
\hline $\begin{array}{l}\text { São João } \\
\text { del Rei - MG }\end{array}$ & $\begin{array}{l}\text { - Missa } \\
\text { - Alvoradas } \\
\text { - Imperador perpétuo } \\
\text { - Sto. Antônio } \\
\text { - Procissão do } \\
\text { Imperador perpétuo }\end{array}$ & $\begin{array}{l}\text { - Mastro } \\
\text { - Pomba } \\
\text { - Bandeiras }\end{array}$ & $\begin{array}{l}\text { - Folias } \\
\text { - Cavalgada } \\
\text { - Congada } \\
\text { - Marujada } \\
\text { - Catuapés } \\
\text { - Bate-paus } \\
\text { - Moçambique } \\
\text { - Dança de fitas } \\
\text { - Pastoras } \\
\text { - Missa inculturada }\end{array}$ & $\begin{array}{l}\text { - Não há referência sobre } \\
\text { políticas locais de preservação } \\
\text { de patrimônios culturais } \\
\text { materiais e imateriais nem } \\
\text { de turismo e cultura. }\end{array}$ \\
\hline $\begin{array}{l}\text { Pirenópolis } \\
\text { - GO }\end{array}$ & $\begin{array}{l}\text { - Missas } \\
\text { - Novenas } \\
\text { - Procissões } \\
\text { - Auto das } \\
\text { pastorinhas }\end{array}$ & $\begin{array}{l}\text { - Pomba } \\
\text { - Bandeira } \\
\text { - Mascarados }\end{array}$ & $\begin{array}{l}\text { - Cavalhada } \\
\text { - Folias para captar } \\
\text { recursos } \\
\text { - Curucucus }\end{array}$ & $\begin{array}{l}\text { - O município foi tombado } \\
\text { como patrimônio histórico } \\
\text { em } 1990 .\end{array}$ \\
\hline $\begin{array}{l}\text { Vale do } \\
\text { Guaporé } \\
\text { - RO }\end{array}$ & $\begin{array}{l}\text { - Missa do Envio } \\
\text { - Novena }\end{array}$ & $\begin{array}{l}\text { - Arca contendo: } \\
\text { coroa, bandeira, } \\
\text { toalhas do altar e } \\
\text { livros de ata } \\
\text { da festividade } \\
\text { - Imperador } \\
\text { Imperatriz }\end{array}$ & $\begin{array}{l}\text { - Procissão fluvial } \\
\text { - Foliões }\end{array}$ & $\begin{array}{l}\text { - Não há referência sobre } \\
\text { políticas locais de preservação } \\
\text { de patrimônios culturais materiais } \\
\text { e imateriais. } \\
\text { • Há um mapa turístico } \\
\text { disponibilizado pelo governo } \\
\text { do estado. }\end{array}$ \\
\hline
\end{tabular}

\section{Considerações finais}

Caracterizadas pela mistura entre o sagrado e o profano, as comemorações em honra ao Divino Espírito Santo nos territórios avalia- dos são festividades católicas antigas de influência dos colonizadores portugueses que se espalharam por todo território nacional e foram se adaptando à geografia e costumes locais características étnico-culturais. Muitas mantive- 
ram suas marcas mais peculiares como a presença de determinados símbolos como o mastro, a bandeira e a pomba branca, a presença de rituais católicos como missas, alvoradas e novenas, traço do colonizador português.

Foram descritas, ainda que brevemente, particularidades culturais: religiosas, manifestações folclóricas, símbolos advindos do colonizador que interagiram com as tradições culturais dos negros "evangelizados" que mantiveram seus ritmos, suas cores vibrantes, seus instrumentos musicais de percussão que inspiram os devotos.

Percebe-se, pelos dados encontrados, que os poderes locais precisam olhar mais detidamente para a inserção das festas na agenda política para a preservação dos patrimônios culturais ali existentes. Há, em algumas localidades o investimento em políticas de turismo, já que a Festa do Divino promove o desenvolvimento local e regional.

A pesquisa também demonstrou que faltam resultados científicos mais abrangentes que possam comparar semelhanças e diferenças entre essas festas no Brasil.

Os autores agradecem a Bolsa de pesquisa concedida pela FAEP - Fundação de Amparo ao Ensino e à Pesquisa de Mogi das Cruzes.

\section{Bibliografia}

ALVES, Elder. Diversidade Cultural, Patrimônio Cultural Material e Cultura Popular: a Unesco e a Construção de um Universalismo Global. Revista Sociedade e Estado, Vol. 25, n 3, 2010. Disponível em: http://www.scielo.br/ pdf/se/v25n3/07.pdf. Acessado em 24/06/2017.

ARAÚJO, Ana Maria. A cultura e a memória da Festa do Divino de Mogi das Cruzes. Projeto História, São Paulo, 2004. Disponível em: https:// revistas.pucsp.br/index.php/revph/article/viewFile/10453/7788. Acessado em: 14/06/2017.
BONINI, Luci M. M.; PEREIRA, Rute (orgs.). Rezadeiras e Rezadores da Festa do Divino Espírito Santo em Mogi das Cruzes, SP: Os saberes e fazeres como patrimônio cultural. São Paulo: Editae, 2015.

BORGES, Wilmer. Vale do Guaporé: começa em Porto Murtinho o 123 Festa do Divino Espírito Santo e chega a Pimenteiras 22 de Abril. Hoje Rondônia, 2017. Disponível em: http://hojerondonia.com/vale-do-guapore-comeca-em-porto-murtinho-o-123a-festa-do-divino-espirito-santo-e-chega-a-pimenteiras-22-de-abril/. Acessado em: 21/07/2017.

BRASIL. Ministério da Cultura. Fundo Nacional de Cultura. Brasília: Ministério da Cultura, 2017. Disponível em: http://www.cultura.gov.br/editais-da-cultura. Acessado em: 24/06/2017.

BRASIL. Decreto No 3.551, de 4 de Agosto de 2000. Institui o Registro de Bens Culturais de Natureza Imaterial que constituem patrimônio cultural brasileiro, cria o Programa Nacional do Patrimônio Imaterial e dá outras providências.Disponível em: http://www.planalto.gov.br/ccivil_03/ decreto/d3551.htm. Acessado em 23/07/2017.

BRASIL. Instituto Brasileiro de Geografia e Estatística (IBGE). Cidades. 2010, 2016, 2017. Disponível em: http://www.ibge.gov.br. Acessado em: 14/06/2017.

CARVALHO, Karoliny. Análise do potencial turístico da Festa do Divino Espírito Santo em Alcântara, Maranhão, Brasil. Turismo \& Sociedade. Curitiba, v. 9 , n. 1, p. 1-18, janeiro-abril de 2016.

CASTRO, Maria L.V. de, FONSECA Maria Cecília L. Patrimônio imaterial no Brasil. Brasília: Educarte, 2008.

CHAVES, Robson. Festa do Divino em Mogi das Cruzes. Revista Nures, PUC, 2010. Disponível em: http://www.pucsp.br/nures/revista15/RobsonChaves.pdf. Acessado em: 24/06/2017.

CRUZ, Nonato. Vale do Guaporé se prepara para receber visitantes na Festa do Divino. Governo do Estado de Rondônia. 2016. Disponível em: http://www.rondonia.ro.gov.br/vale-do-guapore-se-prepara-para-visitantes-na-festa-do-divino/. Acessado em: 21/07/2017.

FERRETI, Sérgio. Festa do Divino no Maranhão. Catálogo da Exposição Divino Toque do Maranhão. Rio de Janeiro: Centro Nacional de Folclore e Cultura Popular /IPHAN / MEC, 2005, p 9-29. Disponível em: http://www.gpmina.ufma.br/pastas/ doc/Festa\%20do\%20Divino\%20no\%20Maranhao. pdf. Acessado em 13/07/2017. 
GOMES, Cristiane. Turismo, Cultura e a Festa do Divino em Alcântara (MA): Meu canto não pode parar. Fortaleza, CE: EdUECE, 2017.

GOMES Cristiane M.; GASTAL, Suzana; CORIOLANO, Luzia Neide. Hospitalidade na Festa do Divino: Seu Festejar em Alcântara e São Luís do Maranhão. Revista Cenário. Vol. 3 no. 5. UnB. Brasilia. 2015.

LOSSIO, Rúbia; PEREIRA, César. A importância da valorização da cultura popular para o desenvolvimento local. Anais do III ENECULT. Salvador, BA, 2007.

MARIANO, Neusa. De todas as Cruzes de Mogi o Divino Espírito Santo também faz festa em Biritiba Ussu. XIX Encontro Nacional de Geografia Agrária, São Paulo, 2009. Disponível em: http://www.geografia.fflch. usp.br/inferior/laboratorios/agraria/Anais\%20XIXENGA/artigos/Mariano_NF.pdf. Acessado em 14/06/2017.

PAKAAS.NET. Festa do Divino Espírito Santo, Vale do Guaporé. Disponível em: http://www.pakaas. net/di1.htm. Acessado em: 21/07/2017.

PASSARELLI, Ulisses. Jubileu Perpétuo do Divino Espírito Santo Paráclito. O Grande Matosinho, 2004. Disponível em: http://www.ograndematosinhos.com. br/artigos/10.htm. Acessado em: 14/07/2017

PREFEITURADE ALCÂNTARA. Festa do Divino tem apoio do Governo do Estado e Prefeitura de Alcântara. Disponível em: http://alcantara.ma.gov.br/noticias/noticias/exibe/7582. Acessado em 23/07/2017.

PREFEITURA DE MOGI DAS CRUZES. Decreto 7.970/2007. Disponível em: http://www.comphap.pmmc. com.br/arquivos/44_2009.pdf.Acessado em: 23/07/2017.

PREFEITURA DE PIRENÓPOLIS. História de Pirenópolis. Disponível em: http://www.pirenopolis. go.gov.br/municipio. Acessado em 21/07/2017.

PREFEITURA DE SÃO JOÃO DEL REI. Disponível em: http://saojoaodelrei.mg.gov.br/pagina/2182/Turismo. Acessado em: 23/07/2017

PORTAL DO DIVINO. Festa do Divino em São João del Rei - MG. Disponível em: http://www.portaldodivino.com/Brasil/jubileu.htm\#1. Acessado em 14/07/2017

RONDÔNIA. Secretaria de turismo. SETUR RO. Superintendência Estadual do Turismo, RO. Disponível em: http://www.rondonia.ro.gov.br/setur/. Acessado em 23/07/2017

SILVA, Liliane; SANTOS, Edilaine; BONINI, Luci. O uso do youtube para preservação da memória: a Festa do Divino em Salesópolis, Biritiba Mirim e Mogi das Cruzes. Diálogos Interdisciplinares, vol. 6, no 1, 2017. Disponível em: https://revistas.brazcubas.br/index.php/dialogos/article/view/230/353. Acessado em: 14/06/2017

SILVA, Mônica. A festa do Divino: Romanização, Patrimônio e Tradição em Pirenópolis (1890-1988). Dissertação apresentada no Programa de Mestrado em História das Sociedades Agrárias. Universidade Federal de Goiás, 2000.

SIMÕES, Maria de Lourdes (org.). Identidade Cultural e Expressões Regionais: estudos sobre literatura, cultura e turismo. Ilhéus, BA: Editus, 2006. SOARES, Marina. Dossiê IPHAN. Festa do Divino Espírito Santo: Pirenópolis - GO. s/d. Disponível em: http://portal.iphan.gov.br/uploads/ckfinder/arquivos/Dossie festa \%20do divino pirenopolis. pdf. Acessado em: 23/07/2017.

UNESCO. Recomendação para a salvaguarda da cultura tradicional e popular. Paris, 1989.

VALIM, Márcia; PRADOS, Rosália; BONINI, Luci. Políticas culturais, processos semióticos: A bandeira e a Festa do Divino em Mogi das Cruzes, São Paulo. PragMATIZES - Revista Latino Americana de Estudos em Cultura. Ano 5, n 8, 2015. Disponível em: http:// www.pragmatizes.uff.br. Acessado em: 14/06/2017.

\section{Recebido em 31/07/2017 Aprovado em 05/09/2017}

I Débora B. G. Thomsen. Especialista em Psicopedagogia e graduada em Pedagogia e Design de Interiores pela Universidade Braz Cubas e Mestranda em Políticas Públicas pela Universidade de Mogi das Cruzes. Contato: debora@palle.com.br

II Rosália Maria Netto Prados. Doutora Semiótica e Linguística Geral pela Universidade de São Paulo. Docente no Programa de Mestrado em Políticas Públicas da Universidade de Mogi das Cruzes. Contato: rosalia.prados@gmail.com

III Luci Mendes de Melo Bonini. Doutora em Comunicação e Semiótica pela PUC-SP. Docente no Programa de Mestrado em Políticas Públicas da Universidade de Mogi das Cruzes e do Mestrado em Habitação: Planejamento e Tecnologia do Instituto de Pesquisa Tecnológica - SP. Contato: lucibonini@gmail.com 